\title{
Semiótica y cultura \\ La semiosis del rito dancístico pascol en la cosmovisión de los rarámuri de la baja tarahumara
}

\author{
Semiotics and culture \\ Semiosis of the pascol dance ritual in the \\ world view of the rarámuri of baja tarahumara \\ Semiótica e cultura \\ a semiose do rito pascol na cosmovisão \\ dos rarámuri da baixa tarahumara
}

Fecha de entrega: 20 de septiembre de 2014 Fecha de evaluación: 15 de noviembre de 2014 Fecha de aprobación: 15 de diciembre de 2014

Juan Pablo Garrido López*

\section{Resumen}

Este artículo pretende realizar un análisis semiótico del rito dancístico del pascol, el cual se distingue por ser una de las prácticas culturales más importantes de los indígenas rarámuri que radican en la región de barrancas de la sierra occidental del noroeste de México. A través del análisis de la semiosis de este rito dancístico intentaremos mostrar cómo es el proceso de significación interpretativa que le otorgan los

Maestro en Antropología con especialidad en Etnología por el Instituto de Investigaciones Antropológicas de la Universidad Nacional Autónoma de México (UNAM). Doctorante en Sociología de la Facultad de Ciencias Políticas y Sociales (FCPyS) de la Universidad Nacional Autónoma de México (UNAM). Correo de contacto: juanpasmr@hotmail.com. 
rarámuri para explicar su cosmovisión. Se tendrá como finalidad dar cuenta que esta práctica cultural es un símbolo esencial del proceso de la asociación de signos cuya acción o influencia compone una parte sustantiva de la cosmovisión de este grupo étnico, que tiene entre sus principales funciones mantener algunos preceptos socioculturales para la estabilidad futura de las familias y la comunidad.

Palabras clave: semiótica, semiosis, cosmovisión, baja tarahumara, fiestas, rito y danza pascol.

\section{Abstrac}

This article tries to make a semiotic analysis of the dance ritual of Pascol, which is distinguished as one of the most important cultural practices rarámuri indians who live in the region of canyons in the western hills of northwestern Mexico. Through the analysis of semiosis's dance this rite try to show how the process of interpretive significance that give rarámuri to explain their worldview. It will aim to realize that this cultural practice is an essential symbol of the process of the association of signs whose action or influence up a substantial part of the worldview of this ethnic group, which has among its main functions keep some sociocultural precepts for stability future of families and the community.

Keywords: Semiotics, semiotics, worldview, low Tarahumara, fiestas, ritual and dance pascol.

\section{Resumo}

Este artigo pretende realizar uma análise semiótica da dança pascol, a qual se distingue por ser uma das práticas culturais mais importantes dos indígenas rarámuri, originais da região de barrancas, na serra ocidental do noroeste do México. Através da análise semiótica dessa dança tentamos mostrar como é o processo de significação interpretativa outorgada pelos rarámuri para explicar sua visão de mundo. Temos como finalidade exemplificar que esta prática cultural é um símbolo essencial do processo da associação de signos cuja ação ou influência compõe uma parte substantiva da cosmovisão deste grupo 
ético, que tem, entre suas principais funções, manter alguns preceitos socioculturais para a estabilidade futura das famílias e da comunidade.

Palavras-chave: Semiótica, semiose, cosmovisão, baixa Tarahumara, festas, rito, dança pascol.

\section{Introducción}

El presente artículo tiene como finalidad realizar un análisis semiótico del rito dancístico pascol para comprender cómo son las condiciones en que se configura la cosmovisión de los indígenas rarámuri o tarahumaras ${ }^{1}$ que radican en la zona de barrancas dentro de región baja tarahumara en Chihuahua, México. A través del análisis de la semiosis de este rito dancístico intentaremos mostrar cómo es el proceso de significación interpretativa que le otorgan los rarámuri para explicar su cosmovisión. Se tendrá como finalidad dar cuenta que esta práctica cultural es un símbolo esencial del proceso de la asociación de signos cuya acción o influencia compone una parte sustantiva del sistema de creencias de este grupo étnico, que tiene entre sus principales funciones mantener algunos preceptos socioculturales para la estabilidad futura de las familias y la comunidad.

El artículo está organizado en tres partes. En la primera parte se encuadra muy brevemente algunos de los elementos teóricos más básicos de la semiótica de Peirce, particularmente cuando él define la semiosis como la acción o influencia que implica una cooperación de tres sujetos, el signo, el objeto y el interpretante. Estos elementos teóricos nos servirán de marco para el análisis posterior del fenómeno ${ }^{2}$ ritual dancístico. Por supuesto, este apartado es muy reducido tanto por cuestiones de espacio como por el dominio que implica la complejidad de la semiótica peirceana.

En la segunda parte se lleva a cabo el análisis semiótico del pascol; pero para ello antes se describe a grandes rasgos cuáles son sus principales características. Para llegar a alcanzar sus detalles se presenta un panorama general de la región de las barrancas,

1 Tarahumara es una hispanización del nombre indígena rarámuri que, etimológicamente, significa "planta (del pie) corredora" (González, R., 1982). En este artículo se utilizará el término rarámuri.

2 Por fenómeno se entiende aquella percepción que a través de los sentidos observa las cosas tal y como son en el mundo y en la realidad. En otras palabras, es el estudio de las cosas tal y como aparecen en el mundo cuya intención no es generar juicios o depositar valores en ellas, sino describir el mundo como se presenta. 
de las festividades, ritos y danzas que conforman la cosmovisión de este grupo étnico con el objetivo de distinguir la importancia y la acción que allí cumple el pascol. Una vez lograda esta tarea se seleccionan lo signos más significativos para iniciar el análisis del proceso de su semiosis y ofrecer una interpretación en la que se destaca qué es lo que hace que este rito dancístico sea un símbolo tan distintivo en la cultura rarámuri. En la tercera y última parte se encuentran algunas conclusiones.

\section{La semiótica de Charles S. Peirce}

En el continente americano, en Estados Unidos, Charles Sanders Peirce fue el creador de una compleja teoría de los signos. Su intención era precisamente entender cuál es la importancia de la naturaleza de los signos por lo cual a mediados del siglo XIX inició una ardua investigación científica y filosófica entorno a este tema. La originalidad de su trabajo ha tenido muchas repercusiones en varias disciplinas de las ciencias naturales, las sociales y las humanidades.

Debido a la formación académica de Peirce su semiótica se constituye de fundamentos de la lógica y la filosofía. La semiótica peirceana se cuestiona por la relación que tienen los signos entre sí, con el mundo y el lugar que tiene el hombre en esta relación (Peirce, 1986). En este sentido, de manera muy general, Peirce señala que el signo puede ser concebido como: general, tríadico y pragmático. O en otras palabras dice que: un signo es algo que está para alguien, por algo, en alguna relación (Ibíd., 1986). Esto quiere decir que el signo peirceano es algo que para alguien representa o se refiere a algo en algún aspecto o carácter. Se dirige a alguien, a un sujeto, en el que crea en su mente un signo equivalente o quizá, más desarrollado, donde al final del proceso le otorgará un uso y una función.

Para Peirce, el signo es lógico-pragmático, es decir, lo importante es saber qué es lo que hace el signo, o bien qué hacen los signos, pues para Peirce los signos representan objetos al producir lo que él llama interpretantes. En este planeamiento el signo siempre está en una relación estrecha con el objeto que representa y también está en una relación con el sujeto para quien es signo. En síntesis, Peirce concibe el signo en una relación tríadica relacional que puede quedar expresada básicamente de la siguiente manera: los signos en sí mismos, los signos en relación a su objeto y los signos en relación a su intérprete. 
Las condiciones epistemológicas que Peirce desarrolló al plantear las relaciones tríadicas del signo profundizaban sobre una comprensión de la realidad de manera más plural y comprometida, lo que a su vez lo llevarían tajantemente a rechazar aquellos modelos dualistas por considerarlos cargados de psicologismos. ${ }^{3}$

Para ello Peirce formuló, dentro de una clasificación mucho más compleja, tres categorías fundamentales del signo que llamó: Primeridad, Segundidad y Terceridad. Señaló que está relación tríadica implica la generación final pero no última de un pensamiento o significado: un hábito. Y planteó que para considerarlo signo este debe cumplir tres condiciones:

1. Es un signo en sí mismo que no indica a ningún objeto,

2. Debe tener un objeto de relación que indica que una relación existe para objetos o términos,

3. La última condición y la más importante, es que la relación semiótica debe ser tríadica: comportar un representamen que debe ser reconocido como el signo de un objeto a través de un interpretante (Peirce, 1987).

En la exploración de los signos Peirce clasificó muchos tipos de signos. En esta tarea distinguió variedades de objetos e interpretantes. En cuanto a los objetos los clasificó en dos: el inmediato y el dinámico. El objeto inmediato es el objeto tal y como se conoce en el signo. Es por así decirlo, el objeto visto desde el interior del signo. El objeto dinámico es aquel que está en su totalidad, es decir, fuera del alcance de cualquier signo o proceso semiótico finito. Es el objeto tal y como se le conocería a largo plazo, en palabras de Peirce, "el Objeto en aquellas relaciones que el estudio final e ilimitado mostraría que hay”.

Con respecto a los interpretantes Peirce señaló tres posibilidades. La clasificación de estos que aquí interesa destacar resalta la idea más general y se divide en interpretantes emocionales, enérgicos y lógicos. El emocional, como su nombre lo dice, genera una

3 En Europa, la llamada semiología cuyo precursor fue Ferdinand de Saussure (1985) dio cuenta del signo lingüistico desde una visión dualista y estructural, proponiendo que este se compone de dos elementos: una imagen material (imagen acústica) que llamó significante y una imagen mental referida a la idea o concepto que llamó significado, ambos conforman el signo. Este es un punto de partida hacia el avance de otras relaciones duales como lengua/habla; sincrónico/diacrónico; forma/sustancia, entre otras unidades. 
emoción, es inmediato y una totalidad cualitativa que corresponde a la categoría de la primeridad. El enérgico es un signo que genera una acción particular, este en una categoría diádica porque se da solo como producto de una categoría bruta y mecánica con otra cosa, y pertenece a la segundidad. El lógico no es ni un sentimiento ni una acción sino algo de orden general, un concepto, corresponde a la terceridad y a la categoría tríadica.

El interpretante emocional se vive en el presente. El energético se da y de inmediato se relega al pasado. Pero el interpretante lógico, por ser conceptual, se dirige hacia el futuro; y para ser efectivo y significar, tiene que ser constantemente interpretado por nuevos interpretantes a futuro. Una condición fundamental de estas categorías es que son ordinalmente relacionadas; esto quiere decir que puede haber primeridad sin las otras dos categorías, pero no puede haber terceridad sin que incluya primeridad y segundidad. Esto supone que puede haber interpretantes emocionales sin más. En cambio, los interpretantes energéticos que se dan encierran forzosamente un aspecto cualitativo, es decir, una carga afectiva. Y, según la clasificación de Peirce, los interpretantes lógicos tienen que reflejar elementos emocionales/cualitativos y también elementos empíricos o singulares.

Peirce propone una clasificación de los signos en un total de nueve clases, las cuales están derivadas en función de las tres categorías del signo. De estas nueve clases de signos la que interesa destacar para los fines de este artículo es la que refiere al ícono, índice y símbolo, aquella en la que el signo está en relación con el objeto ${ }^{4}$. Peirce enuncia que el ícono se constituye de tres tipos: imágenes, diagramas y metáforas. La imagen tiene la cualidad de ser semejante a algo, por ejemplo, con base a un color o una forma y puede ser un retrato o una fotografía. El diagrama es una relación y la semejanza que guarda con su objeto, funciona con base a una similitud de los elementos del signo y los elementos del objeto, ejemplo de ellos es un mapa o un plano. Finalmente está la metáfora que tienen las cualidades de explotar el carácter

4 Simplificadamente, las nueve clases de signos tienen las siguientes características. Peirce señala que considerado el signo en sí mismo un signo puede ser una mera cualidad que él llama "cualisigno"; un existente actual es un "sinsigno"; y una ley general un "legisigno". Cuando el signo se relaciona con su objeto al tener algún carácter en sí mismo, Peirce lo llama un "icono"; con alguna relación existencial con ese objeto es un "índice"; y alguna relación con el interpretante es un "símbolo". La última clase, el interpretante de un signo lo representa como un signo de posibilidad, lo que el autor llama un "rema"; un signo de algún hecho es un "dicisigno"; y un signo de la razón es un "argumento" (Peirce, 1987). 
representativo del objeto, ya que estas son susceptibles de producir interpretantes que son similares a sus efectos.

La semiótica no solo tiene por objeto los signos en cuanto a su naturaleza, tipos y clases, sino que también se ocupa de la concepción del sentido, pues que una cosa se encuentra idónea para ser un signo de un objeto, es decir, para representarlo, esa cosa, el signo, logra representar al objeto al producir un interpretante, y por lo tanto, nos lleva a la condición de que los agentes son significadores de su cultura (Ibíd., 1987).

Los signos contienen significados desde el momento en que se les utiliza y se les reproduce en la cultura. Esto quiere decir dos cosas: la primera es que el uso es generador y productor del significado; la segunda es que la significación no se da en el vacío sin base, sino que requiere de un marco cultural en donde al final se genera la significación o el intrepretante.

El análisis semiótico del rito dancístico pascol es complejo debido a la amplitud de los lugares y momentos donde aparece, que prácticamente es a lo largo de todo el año. Como se tratará de analizar, este rito y danza se presenta como una configuración del mundo rarámuri, dispositivo que acciona la cosmovisión, es parte de un continum, es decir, no es una práctica cultural aislada, sino es parte intrínseca y sustantiva del sistema de creencias religiosas que se articulan con el ordenamiento de la vida social y comunitaria del grupo rarámuri barranqueño.

Dada la amplitud del pascol en la cultura de los rarámuri de la baja tarahumara o zona de barrancas las cosas o los signos que componen a esta danza-rito bien pueden simbolizar su objeto. Puesto que los signos, los objetos y los interpretantes son funcionales y no que una cosa tenga que ser una u otra forzosamente, el pascol en un momento dado puede ser un signo pero igual puede convertirse en el objeto sobre lo que se habla de él, y desde luego puede ser también un interpretante. La semiosis es contextual, y depende del punto de vista del que hace el análisis.

De esa manera para explicar la semiosis del pascol he elegido como contexto las festividades, ritos y danzas, así como el ciclo agrícola, que suceden a lo largo de un año en las comunidades rarámuri barranqueñas situadas en la denominada baja tarahumara. 


\section{El tiempo y el espacio de las festividades, los ritos y danzas y la agricultura de los rarámuri}

La importancia que ha tenido la naturaleza para los rarámuri de la región baja es esencial para el correcto funcionamiento de la vida social, económica, política y cultural. Hoy, en el siglo XXI no hay grandes diferencias respecto a la preeminencia que tiene la naturaleza y su relación con la vida comunitaria de los rarámuri. Para una sociedad que desde hace siglos y hasta la fecha se ha dedicado a la agricultura y a la ganadería rudimentarias, así como a la recolección y eventualmente a la caza, la relevancia de los conceptos de tiempo y espacio son vitales. Dentro de estas dos categorías está el funcionamiento de la sociedad y por lo tanto del sistema de creencias religiosas en cuyas deidades recae la confianza de la sociedad.

Por tiempo y espacio debe entenderse concretamente la referencia a los mesescalendario y a las temporadas climáticas-agrícolas, respectivamente. En otras palabras, debe entenderse el conjunto de festividades, ritos y danzas, así como el ciclo de agricultura que suceden de manera concatenada a lo largo del año y que entienden y practican los rarámuri de la baja tarahumara. De esta manera la naturaleza (clima, temporadas de lluvia y sequia) y la cultura (fiestas, ritos, danzas) están rígidamente relacionadas entre sí, lo que quiere decir entonces que naturaleza y cultura no son cosas aisladas sino parte de una misma unidad.

Si utilizáramos la forma de un reloj de manecillas para observar la relación de las fiestas, ritos-danzas y agricultura que suceden a lo largo del año en la baja tarahumara, podría apreciarse de la siguiente manera: 


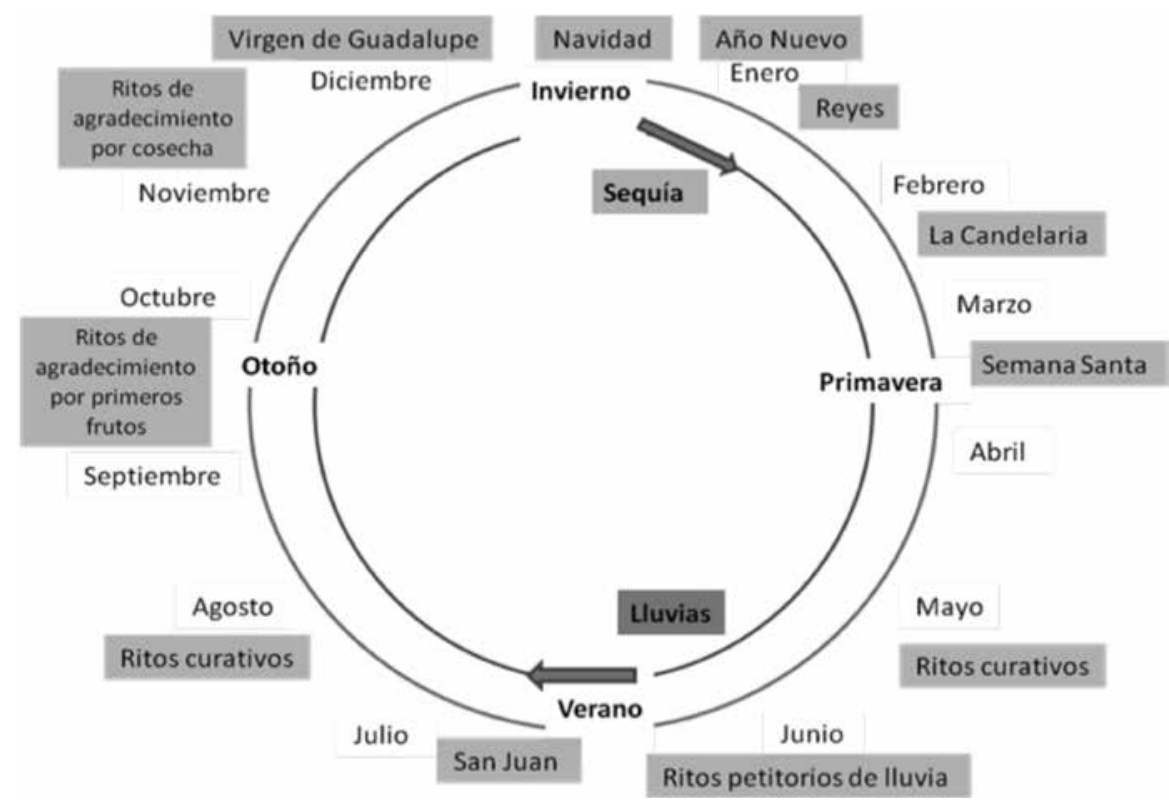

\section{Articulación de las festividades con ritos y danzas pascol en los periodos climáticos de la región baja tarahumara}

Los elementos de análisis aquí presentados han sido seleccionados según la relevancia otorgada por los propios agentes rarámuri, así como por la información cualitativa y las observaciones etnográficas ${ }^{5}$ realizadas en las fiestas de los ritos, las danzas y el ciclo agrícola anuales de la zona de barrancas ${ }^{6}$. La separación de estos eventos en

5 Por emic entenderemos, adoptando la posición de Kenneth Pike L. (1967), la labor que el científico social $u$ otros observadores sociales, intentan al reproducir los contenidos culturales tal como se les aparecen a los individuos humanos (actores, agentes) que pertenecen al pueblo o cultura de referencia, o bien, cuando tratan de reproducir las operaciones que los sujetos agentes Ilevan a efecto para realizar tal o cual contenido cultural. Por etic en cambio, se entenderá la labor del científico social (etnólogo, antropólogo, sociólogo) u otro observador al tratar de reproducir o al menos fijar, las coordenadas de esos contenidos culturales a partir de factores que acaso no son percibidos como internos por los miembros de ese pueblo o agente de referencia.

6 Los elementos de análisis que enseguida se presentan son resultado de observaciones etnográficas realizadas durante nueve años a través de varios trabajos de campo en la región de la sierra tarahumara y muy especialmente en la zona de las barrancas. Por lo tanto, la unidad cíclica de "fiestas, ritos, danzas y agricultura" que se describe a continuación son resultado de los análisis realizados en 
apartados es una cuestión meramente heurística que facilita una lectura del fenómeno bajo estudio, empero, por una cuestión metodológica se ha elegido a la ritualidad y danza de pascol debido a que se trata de uno de los conectores más sobresalientes de la cultura rarámuri. Esto quiere decir, en otras palabras, que el pascol es un signo muy amplio capaz de producir otros signos (o interpretantes), de modo que este (el interpretante) puede pude asumir la misma relación con el objeto en la que se encuentra el propio signo. Esta dinámica de su semiosis la desarrollaré un poco más adelante.

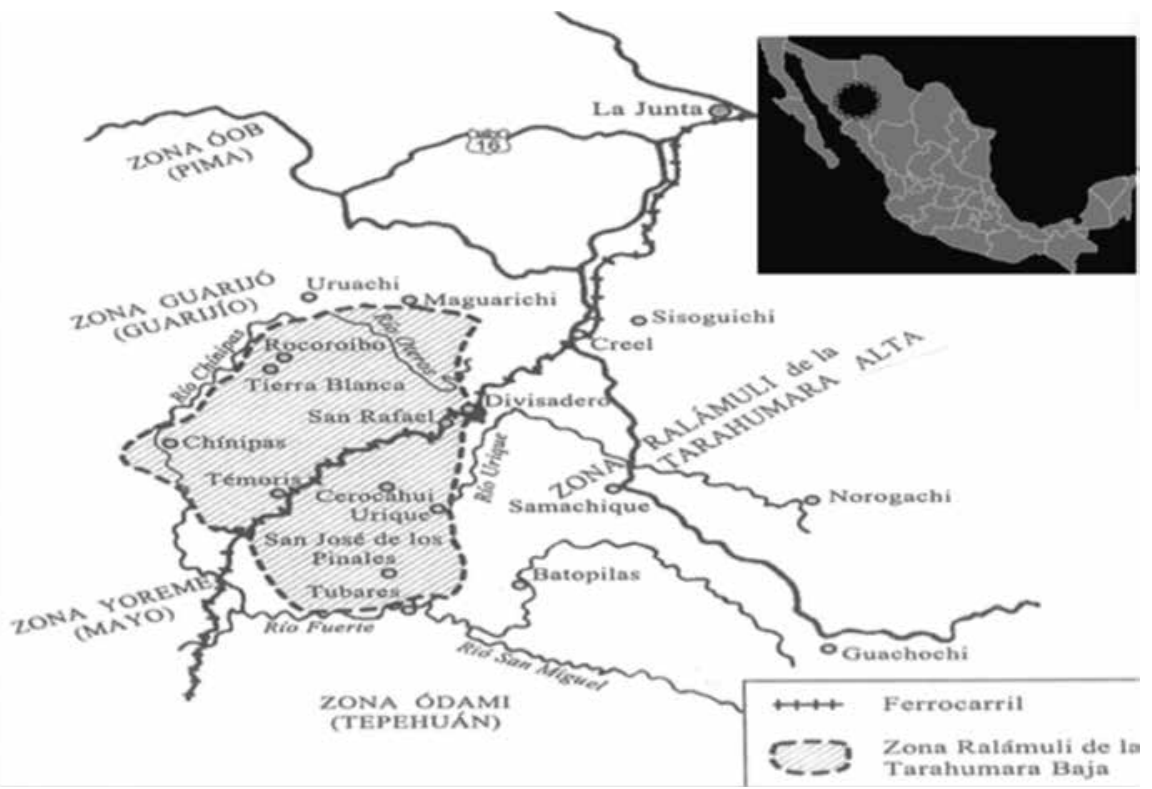

Fuente: Don Burgess (2002). Mapa de la Sierra Tarahumara y entre líneas punteadas la zona de la baja tarahumara, en Chihuahua, México.

\section{Los contextos de la semiosis del pascol. El clima y las fases del ciclo agrícola anual}

Para la mayoría de las comunidades que se localizan en la barranca -cuya altura promedio oscila entre los $500 \mathrm{msm}-$, el primer indicador sobre la aproximación de las lluvias son las nubes de color obscuro que aparecen visualizadas en lo alto detrás

la zona de las barrancas y que han dado como resultado dos trabajos de investigación (autor, 2006, 2012a, 2012b). 
de los cerros. En esta zona de clima tropical la temporada de lluvias inicia aproximadamente hacia finales del mes de junio (se toma como fecha de partida el día 24 - día de San Juan-. Por lo que a partir de ese momento la comunidad espera con ansiedad que aparezcan en el cielo azul las nubes obscuras indicadoras de la llegada de las lluvias. Esta espera impacienta enormemente a la comunidad en general. Más aún a los agricultores. No es para menos, pues del agua dependen la agricultura, los alimentos y una serie de fiestas, ritos y danzas.

La aparición de las nubes cargadas de agua está acompañada de otro indicador que para los rarámuri hace más próxima la llegada de las primeras lluvias, -sobre todo después de la sequía y el extremoso calor que marcaron los meses anteriores-, ellos se refieren a los primeros estallidos de los rayos. El estruendoso sonido proviene de la sierra y su eco viaja por lo angosto de la barranca. La profundidad de la barranca permite presenciar claramente el evento, la luminosa caída de los rayos hacia la tierra y los pinos. Si la llegada de las lluvias es exacta habrá más esperanza de que las siembras salgan beneficiadas. En esta zona de la barranca la finalización de la temporada de lluvias ocurre a finales de septiembre o principios de octubre.

La fecha de siembra de maíz es del 20 de junio al 25 de julio. Se deshierba y fertiliza durante el mes de agosto. La cosecha se realiza a partir del 20 de octubre y todo noviembre. Solo se siembra una vez al año. La siembra del fríjol es del 25 de julio hasta el 15 de agosto. Se deshierba y fertiliza durante el mes de agosto. La cosecha se efectúa del 20 de octubre y abarca todo noviembre. Eventualmente la última quincena de febrero se puede sembrar frijol dependiendo de las lluvias invernales. Se deshierba y fertiliza en todo marzo y se cosecha a finales de mayo, el día 25.

\section{Los marcos festivos de la ritualidad y danzas rarámuri}

La vida social y religiosa de los rarámuri en la barranca tarahumara se basa en un sistema interrelacionado de festividades, ritos y danzas con profundas correspondencias con todas las fases del ciclo agrícola anual. El sistema en su conjunto se desenvuelve en una serie de ritmos y secuencias que ocurren en periodos de tiempo y espacios determinados sucedidos durante un año. 
En la barrancas ocurren tres conjuntos de festividades en los que para cada uno se realizan tres tipos danzas ${ }^{7}$, así como una serie de ritos correspondientes. Primero, la que se realiza el 12 de diciembre dedicada a la virgen de Guadalupe, siguen Navidad el 24, Año Nuevo el 31, Reyes el 6 de enero y Candelaria el 2 de febrero, en las que se ejecutan danzas de matachín y pascol. Este conjunto de fiestas tienen la intención de agradecer a Dios por las cosechas agrícolas recolectadas a finales de noviembre y ofrecer en su honor la fiesta principal ofrecida a la virgen de Guadalupe. Esta fiesta se realiza en el ámbito comunitario, en la iglesia y los patios del pueblo.

Segundo, esta es una las fiestas más importantes del año y se hace en días de Semana Santa (jueves, viernes y sábado santos y domingo de resurrección) y que puede celebrarse en los meses de marzo o abril. Esta celebración se caracteriza por la danza de los fariseos y los diablos, pero también hay danza pascol. Esta gran fiesta reinterpreta a la manera rarámuri la muerte y resurrección de Jesucristo. También se realiza en el ámbito comunitario.

Tercero, las que se efectúan a partir del mes de junio hasta noviembre y que se distinguen por las danzas de yúmari-tutuguri y pascol. Estas son un conjunto de celebraciones fuertemente vinculadas con la apertura del ciclo agrícola y la intención de solicitar a dios -a quien llaman onurúame-, por una buena cosecha, buenas lluvias y excelentes frutos. A diferencia de los dos primero grupos de fiestas señalados anteriormente, se realizan en los espacios de la iglesia y el pueblo, este tercer grupo se realiza en los ámbitos domésticos y privados, en los patios de las casas de los rarámuri ${ }^{8}$.

Como puede apreciarse la danza de pascol es la única que está integrada en los tres grupos de celebraciones, por lo que cabe hacerse las siguientes preguntas: ¿por qué para los rarámuri barranqueños esta práctica cultural es más sobresaliente que otras?, ¿qué hace que este rito dancístico sea recurrente y se presente con gran fuerza y notoriedad en cuanto a su reproducción en los diversos contextos festivos? y más aún,

7 Luis González Rodriguez (1984), señaló que las danzas del matachín y el fariseo corresponden a la adopción gracias a la influencia colonial; y las danzas de tutuguri, yúmari y pascol corresponden a lo autóctono.

8 Algunos de los ritos que aún se realizan son: curativos para subir la mollera (cohoyo) del recién nacido, curar el susto del enfermo o del ganado, ritos preventivos contra la caída del rayo (rupunamara remogaka), subir el alma del difunto al cielo, en faenas de trabajo, tesgüinadas y cumpleaños (autor, 2006). 
¿por qué este rito dancístico se puede interpretar como un "sello" sociocultural de la región barranqueña? Veamos en resumen algunas de sus características.

\section{El pascol como un símbolo de la cosmovisión}

El pascol es una danza y bailarlo es un ritual, a quien ejecuta la danza se le llama pascolero/a. El pascol se puede comprender como un signo que esquematiza la cosmovisión e influye decisivamente en la vida cotidiana y la vida religiosa de los rarámuri barranqueños. En lo que se refiere a la vida cotidiana su accionar permite reconstruir significaciones que permiten orientar a los rarámuri en su mundo y dotarlos de experiencia. Pero esta experiencia adquirida no se termina en el momento de concluir la ejecución de la danza ritual, sino que tiene el cometido de cumplir la función de orientar la conducta y el comportamiento social de los rarámuri en el futuro inmediato. Con lo que respecta a la influencia en la vida religiosa, particularmente en la cosmovisión, su orientación está en las acciones comunicativas del propio rito, la danza y pasos, la coreografía, los saludos, los ofrecimientos, entre otros, que conectan con las deidades que gobiernan el mundo de los rarámuri y que son las encargadas de beneficiar o perjudicar el presente y el futuro.

Entre sus atributos se encuentran el amplio campo de acción que abarca. A lo largo del año, en cada fiesta, comparte y alterna el espacio ritual con las danzas de fariseos, matachines y yúmari-tutuguri; es parte integral de una serie de rituales petitorios, preventivos, curativos, rogativos a los santos (autor, 2012) o en otras circunstancias imprevistas, mortuorios para enterrar a los muertos, enviar las almas al cielo y encontrar las almas perdidas, entre otros (Merrill, 1992). Los lugares donde se realiza comprende prácticamente todas las fiestas domesticas (ranchos, en el interior de las casas, patios y en campos abiertos y en algunas puntas de las montañas) y las fiestas comunitarias (adentro y afuera de la iglesia).

En la mayoría de los casos se danza durante toda la noche, madrugada, amanecer y parte de la mañana del siguiente día). El número de danzantes es indeterminado, de

9 La importancia de estudiar la ritualidad en las rancherías rarámuri (ámbito doméstico) sigue siendo una preocupación de los investigadores, debido a que la reproducción de prácticas rituales y danzas en el espacio de ranchería es muy diferente de la realizada en el espacio comunitario. Algunos investigadores han elegido como prioridad las fiestas del ámbito doméstico, cuestión metodológicamente relevante (Pintado, 2007). 
un par o más de treinta, varones y mujeres pueden mezclarse o cada género formar su grupo. Llevan atados en los tobillos uno o dos chayekori ${ }^{10}$; visten ropa que se compone de pantalón de mezclilla tipo vaquero, tenis, huaraches o sandalias (de tres agujeros) y camisa, aunque usan sombrero, en la danza no lo portan. La formación coreografía básica son las figuras circulares de una diversidad que está asociada con nombres y movimientos de animales, donde destacan los pasos con golpeteo al piso de redoble, semiarrastrado y arrastrado con diversidad de formas y un uso marcado del talón, planta del pie y dedo aductor. Suele estar acompañado de música en violín, guitarra y acordeón (autor, 2006).

El pascol ocupa un lugar único en la cosmovisión de los rarámuri de la barranca. Esta se estructura de tres niveles o mundos: el mundo de arriba donde vive el dios que llaman onorúame, el mundo de en medio donde viven los rarámuri (varones, mujeres, niños y ancianos indígenas), y el mundo de abajo en donde vive el diablo ${ }^{11}$, (en ocasiones relacionando a los chabochi que son todos los mestizos no indígenas) (autor, 2011).

En el mundo de arriba vive el dios onorúame, pero también vive allí el sol, el astro solar en palabras de Pedro de Velasco, "las dos imágenes fundamentales de la teología rarámuri -implícita en los ritos o explícita en leyendas, sermones y explicaciones-, son la paterna y la solar, ambas indisolublemente relacionadas entre sí" (Velasco, 1987). En otra referencia de esta dualidad leemos que:

La religión tarahumara puede sintetizarse como de culto astral, ritos de fecundidad y ceremonias para alejar el mal, ritos que les proporcionen seguridad y tranquilidad y les ahuyenten la tristeza y el miedo. [...] Rinden culto al sol, rayénari, al que identifican como onorúame, "el que es padre”. [...] El culto al sol se manifiesta con la reverencia que muestran cuando está por aparecer en el horizonte. [...] Se observa también en el modo reverencial con que se expresan

10 Se trata de un instrumento que está hecho de pequeños capullos de mariposa atados a los tobillos con cuero de piel de chiva que puede medir hasta un metro de largo y que al interior contienen piedritas que al ser agitadas con los pasos de la danza producen sonido con de cascabel.

11 Para William Merrill (1992), la cosmología rarámuri fue reducida en el número de deidades; incluso algunas fueron eliminadas por completo, con lo que se consolidaron los poderes y caracteristicas de la mayoría de las demás deidades, bajo los conceptos modernos de Nuestro Padre y el Diablo. Estas formas se fusionaron para representar en el caso del Diablo, al concepto indigena del señor del inframundo y combinaron a Dios, el Padre, con la deidad indigena padre y creador, la cual está asociada con el sol (Nuestro Padre). 
del sol, en las aspersiones que le hacen mojando un hisopo en el tesgüino. También aparece en los casos en que se anuncia que un niño ha bajado del cielo y pide que le sacrifiquen al sol gallos blancos, borregas blancas, chivos blancos y vacas blancas para aplacarlo. Por culpa de la conducta de los tarahumaras, o por razones que desconocen, el sol está enojado y pide esos sacrificios que, de no hacerse, dicen se les desplomar y los apachurrara a todos; o bien dejará de llover, o nevará intempestivamente y se echaran a perder todos sus sembrados (González, 1982).

Lo anterior no quiere indicar que los rarámuri piensen a Dios como alguien que siempre actúa en su beneficio, como tampoco piensan que el Diablo siempre trabaja en su contra. Como bien señala Merrill (1992), los rarámuri atribuyen inclinaciones y tendencias a estas deidades, que varían en relación a las acciones que ellos tienen para ellos. Los rarámuri saben que Dios y el sol puede actuar en su contra e incluso provocarles la muerte.

\section{La producción de significación interpretativa del pascol en la cosmovisión rarámuri}

En la delimitación por explorar cuál es la relación del pascol con el objeto que representa se derivan algunas cuestiones: ¿cuál es la función del pascol como signo?, ¿cómo funciona su producción sígnica?, ¿cuáles son los nuevos signos que se producen?, ¿cuáles son los signos que se presentan en la dinámica de la producción de los signos? Y finalmente, ¿cómo funciona el pascol para ser tomado o interpretado como un signo primordial de la cosmovisión rarámuri?

En la concepción que tienen del mundo, es decir en su cosmovisión, los rarámuri están situados en el mundo de en medio. Es allí donde realizan sus fiestas, ritos, danzas, donde se establece la agricultura y acontecen los climas, y es ahí donde el pascol adquiere su verdadera eficacia simbólica.

Si observamos la cadena de eventos sociales, culturales y de subsistencia que tienen los rarámuri a lo largo del año, esta queda así: el año climático en la barranca se divide en dos épocas: lluvias y sequia. A partir de estas dos épocas los rarámuri organizan el ciclo agrícola en tres fases: barbecho, siembra y cosecha). Cada una de las fases acciona determinados ritos y danzas. El ciclo agrícola está estrechamente vinculado 
con las festividades religiosas, es decir, de manera simbólica fiestas y agricultura están concatenadas y funcionan complementariamente. Las festividades más importantes se dividen en tres grupos, de la misma manera que las danzas y ritos más importantes también se dividen en tres. Todo esto que ocurre en un año implica que los rarámuri estén activos prácticamente todos los meses. Y por tanto, la compleja relación de estos aspectos hace que el sistema de creencias, y particularmente la cosmovisión, reciba un valor sumamente destacado.

Cuando los rarámuri observan en el cielo las esperadas nubes obscuras comienzan las suposiciones acerca de cómo podrían venir las precipitaciones pluviales. Las señales que dan las nubes lleva a los rarámuri hacia la proximidad o no de las lluvias, estas son el objeto. En la cultura rarámuri esto no quiere decir que el objeto, o sea las lluvias, se vayan a presentar así nada más. Para que el objeto se presente es imperioso comenzar una serie de fiestas domesticas cuyo fin es solicitar a Dios onorúame/sol que no se vayan esas nubes cargadas con agua. Esta señal viene acompañada de la caída de rayos eléctricos, suceso que enlaza la idea de la cercanía de las lluvias. El interpretante de esas señales es el acto de hacer los ritos y las danzas pascol en los ámbitos festivos domésticos que tiene por cometido la petición de las lluvias en los campos agrícolas.

Las consecuencias técnicas de una mala temporada de lluvias, por escasez o falta de agua, lleva a que algunas plantas como el maíz y frijol no maduren como deberían hacerlo o incluso ni siquiera lleguen a dar frutos; las consecuencias simbólicas lleva a que los rituales y danzas que agradecen a Dios/sol por los primeros productos tengan que anularse. Esta privación implica la omisión de otras reuniones festivas o de trabajo que se llaman tesgüinadas (reuniones donde se injiere la bebida tesgüino o sowiki ${ }^{12}$ hecha a base de maíz). Simplemente, no hay cosecha para ofrecer. Este es un asunto muy delicado para una sociedad y cultura que además de depender del maíz y frijol como medio de subsistencia básico, tiene que cumplir con los insumos de la agricultura con los rituales y danzas, convencionalmente establecidos, que manda la costumbre. Así, la presencia de nubes obscuras tienen su relación causal con las lluvias, por lo que este primer signo se convierte en un signo interpretante, que en este caso es hacer las ceremonias pertinentes.

12 El sowiki es una cerveza de maiz fermentada a la que los rarámuri también llaman tesgüino. Es una bebida muy importante que se ingiere en diversos ámbitos de la vida cotidiana, pero que no necesariamente tienen que pertenecer a ámbitos rituales o festivos. Popularmente a la reunión donde se brinda la bebida se le dice tesgüinada. 
Otro efecto práctico negativo que trae el no hacer fiestas, es dejar de realizar las danzas pascol y yúmari-tutuguri. Entre los rarámuri danzar no es un acto de diversión. Danzar tiene una connotación de trabajar (Lumholtz, 1986). Así, todo aquel rarámuri que no trabaja y danza cuando tiene el deber de hacerlo se le llama en su lengua rarámuri sinakuri (holgazán). Danzar está ligado con hacer las adecuadas ceremonias, si no se danza y hace fiesta entonces no se trabaja ni se agradece, respectivamente, y esto en la normatividad de la cultura rarámuri no es aceptado.

La producción de signos del pascol se genera con gran eficiencia en los tres mundos que componen la cosmovisión rarámuri. Pero si gran efectividad se genera y funciona en la vinculación que hace del mundo de en medio con los mundos de arriba y de abajo. Es un signo autóctono que tiene una gran fuerza y reúne en sí mismo diferentes elementos que son capaces de servir como lentes o reflejos de la sociedad y cultura de este grupo étnico.

Si se desglosan los signos que componen al pascol, se puede llegar a saber que pertenece a la clase de símbolo y la categoría de la terceridad. Por lo tanto en él se relacionan las tres clases de signos interpretantes: emocionales, energéticos y lógicos. Estos signos tienen su contenido de la siguiente forma. El primero surge con la emoción que da a los rarámuri mirar y escuchar los pasos y el sonido que provocan las piedritas que están depositadas en los capullos de mariposa que el pascolero lleva atados a sus dos tobillos y que los hace sonar como un cascabel conforme danza y que acompaña como gritos leves y algunas risas. El interpretante enérgico es provocado por la acción particular cuando los rarámuri asistentes se incorporan a la danza haciendo una fila por detrás del pascolero (cabecilla principal) de manera alegre, con risas, pero a su vez con mucha solemnidad. El interpretante lógico es el conceptual, el general, en este caso, produce diversos interpretantes lógicos mediante acciones rituales, como el saludo-despedida a Dios, al sol o al lucero de la mañana ubicado en la posición cardinal del Este cuando se levanta el rostro, o se levanta la mano, o se avienta sowiki al cielo, y también el saludo-despedida al Diablo cuando se avienta sowiki a la tierra y se pisa fuerte el piso formando una cruz, para que este no salga del mundo de abajo donde vive. Este interpretante lógico que se dirige hacia el futuro, y que se compone de la emoción y solemnidad y de las acciones dancístico rituales, establece el medio o el puente comunicativo con las deidades que gobiernan en el mundo de los rarámuri. En los conceptos generales de esta cosmovisión el hacer fiesta y danzar para Dios/sol y el Diablo traerían la estabilidad durante el año, traerían las lluvias, beneficiarían 
con la salud de los rarámuri y de los animales (el ganado), alejarían los males, las enfermedades, la escasez. Sería un año prospero.

En el interior de las fiestas el pascol nos puede llevar a conocer otros aspectos como son la producción de los signos y la relación de estos con el interpretante. Si ahora analizamos en qué consisten los signos ícono, índice y símbolo en esta danza ritual, se podría mencionar lo siguiente. Antes de hacer cualquier fiesta los rarámuri tienen que conocer los signos índices y su relación con los objetos. Es decir, tienen que saber que las nubes obscuras, la caída del rayo, y el día 21 de junio del calendario (día del santo patrono San Juan), son un conjunto de índices que señalan un objeto: la posibilidad o no de que llueva. Sin lugar a dudas, el color obscuro de las nubes, la luminosidad y ruido de los rayos y el silbido del viento son cualidades de forma y color icónicas. Pero sobre el ícono Peirce introduce una clasificación triple: la imagen, el diagrama y la metáfora.

En este caso las cualidades de las nubes como su color, o la luz y el ruido de los rayos y el viento, son imágenes del ícono. La producción de los signos y la relación del objeto con el interpretante pasan al siguiente nivel con el último tipo de ícono, el diagrama. En la danza pascol uno de los elementos rituales más distintivos son los chayekori, que al ser agitados por el pascolero producen un sonido que se asemeja al que hacen las víboras de cascabel. Las serpientes son animales que viven en los aguajes, cañadas y cuevas, que en términos de cosmovisión pertenecen al mundo de abajo. La relación del elemento cascabel (sonido icónico) y la forma (serpiente) funcionan con base en la similitud con el animal. Precisamente aquí entra en juego la metáfora, al dar cuenta del símbolo que este animal representa en la cultura rarámuri que es significado cuando el danzante pisa el suelo con fuerza cuatro veces hacia abajo, lo que simboliza el mundo de abajo. El pascolero al mismo tiempo produce en el suelo una cruz con el danzar de sus pies, esto conceptualiza de manera general la cruz de Dios hecha por un rarámuri para comunicarle al Diablo que no suba al mundo rarámuri, que los rarámuri lo respetan y que lo toman en cuenta, por eso siempre le ofrecen en cada danza (antes de dar el primer paso) un sorbo del preciado sowiki.

El pascol es un símbolo de la cultura rarámuri, particularmente de aquellos que viven en la zona de barrancas. Sus elementos como la parafernalia, los pasos danzas, las coreografías circulares, el saludo y ofrecimiento del pascolero con sowiki al Dios/sol, al Diablo, entre otros más que no pueden ser revisados debido al espacio, engloban la cosmovisión y se accionan a través de la ritualidad y la mitología que la sostiene. 
Para los rarámuri el pascol es un símbolo, porque así ellos lo han acordado, durante siglos lo han puesto en práctica para convenir que mediante su expresión se pueden representar otros objetos del mundo rarámuri, en otras palabras, el danzar pascol y hacer los ritos $^{13}$, no es danzar pascol y hacer los ritos, sino es una regla general que implica otros objetos de la cosmovisión de esta cultura indígena.

La utilización del rito y danza pascol como símbolo siempre está en un contexto determinado, es decir, se trata de un proceso donde su significación cultural está contextualizada a través de marcos culturales establecidos. Los rarámuri saben que si realizan una ceremonia y la danza dentro de un contexto inapropiado, pueden transgredir las reglas de coherencia y cohesión que estipula el contexto y consecutivamente romper las normas sociales-colectivas del sentido. Esta acción significa un adecuado manejo y conocimiento de la práctica ritual, pues según la convención de este símbolo, el ejecutarlo fuera del campo-simbólico-eficaz adecuado podría traer consecuencias negativas contradictorias y deterioro en la cultura rarámuri. Todos los interpretantes que han resultado del uso del signo pascol han forjado un habito de interpretación que hacen que el significado de este rito-danza sea muy consistente. Un ejemplo de esto es la cancelación del pascol durante la época de sequia, pues al realizarlo, dicen los rarámui, podría alejar las nubes que traen el agua (2006).

Esta interpretación es general por parte de los rarámuri. No está en discusión. Sin embargo, al ser un símbolo el pascol, con otros signos que los componen, que por tanto es un signo en desarrollo, entonces necesita de otros signos que lo interpreten. Los profundos cambios que viven las comunidades indígenas en México en la actualidad han generado modificaciones en las cosmovisiones autóctonas. Al cambiar el espacio y el tiempo de la ritualidad también cambian necesariamente la producción sígnica que se mantenía hasta un cierto punto. Los signos que son ahora el pascol se desarrollan y es inevitable que surjan nuevo signos, nuevos objetos y nuevos interpretantes.

13 La sociologia que ha estudiado el rito ha destacado una caracteristica común encontrada en varias sociedades practicantes de ritos, "la repetición es parte inseparable de la esencia misma del rito" (Cazeneuve, 1971). En las prácticas culturales la repetición no implica un mecanismo cerrado, sino la acción encargada de presentar el significado actual (y presente) que los ejecutantes buscan y quieren interpretar. Es una acción que está alli (en un momento) que pretende dejar de estar alli y trasladarse. Y es justamente la apropiación del contexto, que permite al objeto renovarse, transformarse frente aquel y no quedarse estático. Entiéndase al contexto como el espacio donde se determinan y controlan los significados. 
En principio, la cadena semiológica es, pues, infinita puesto que el interpretante es un signo que requiere él mismo un interpretante para significar. Sin embargo en la práctica las cosas no ocurren así. No es necesario volver a recorrer toda la cadena de los interpretantes para determinar la significación de un signo. La razón es que el juego de los signos es contextual (Deledalle, 1996).

\section{Conclusiones}

El estudio a profundidad de la ritualidad y las propiedades simbólicas del pascol rarámuri son un pendiente de las investigaciones etnográficas y etnológicas en la Sierra Tarahumara, llámese alta o baja Tarahumara. No obstante, en los últimos años han surgido algunos trabajos que sitúan al pascol como uno de los ritos-dancísticos más distintivos y de mayor diffusion, no solo del estado de Chihuahua sino en el noroeste mexicano.

Estudios del pascol desde la perspectiva semiótica no hay en la literatura. Este artículo es un intento de mostrar bajo la semiótica peirceana la estructura tríadica de la que se compone este símbolo autóctono de la comunidad indígena rarámuri, que siguiendo a Peirce se manifiesta abierto y social e inserto en una red de relaciones sociales y culturales cuya significación, como vimos en este texto, dependerá del contexto de aparición, así como de la perspectiva del receptor.

El pascol es un símbolo, una acción que porta significados. Su ritualidad es un objeto que los interpretantes direccionan hacia el futuro; es un acto concreto hacia el futuro para esperar algo que siempre se desea sea positivo para las familias y la comunidad rarámuri. Su sentido se transporta en la intencionalidad que intenta pronosticar en el futuro las interpretaciones de una cosmovisión que esté a la par y en armonía con el mundo en el que viven los rarámuri. En esta sociedad profundamente creyente de la religión católica y del culto al astro solar y otros seres, danzar pascol es una gran metáfora que recuerda a los rarámuri el papel y la función que ellos tienen en el mundo de en medio, y lo que deben hacer ellos como comunidad para establecer los correctos vínculos con los otros dos mundos que son creadores benevolentes, pero también destructores y malévolos.

La semiosis del pascol permitió descubrir una pequeña parte del mundo de los rarámuri, cómo es ahora, cómo operan sus signos, cómo se producen en una cadena semiótica 
y la manera en que estos son interpretados. En el desarrollo del planteamiento se reveló que el pascol es un símbolo en el que pueden atravesar distintos procesos de significación que los rarámuri pueden dotar de significado, siendo por la tanto, la creatividad y el pensamiento rarámuri, partes fundamentales de las nuevas semiosis.

En estas nuevas semiosis y construcciones de significado está el pascol en la actualidad, como un elemento que comienza a distinguirse en nuevos escenarios, es decir, contextos de significación en donde antes no se suponía tuviera sentido, sino solo hasta ahora en el momento en que comienza a usarse. En este caso el pascol ha sido usado como un sello de la identidad rarámuri, de la regional de las barrancas, el cual ha comenzado a desarrollarse fuera de las comunidades y fiestas locales para situarse en espacios muchos más amplios y de manera folklorizada; pero estos testimonios necesitarían otro espacio para ser profundizados a detalle, quizá en otro espacio pueden tratarse. El uso, por lo tanto, determina su significado, mismo que se halla inmerso en un futuro. Se significan los nuevos escenarios del pascol en la medida en que este se usa en el presente para significar el futuro.

\section{Referencias}

Acuña, D. (2007). Dimensión Antropológica. Enero-abril, 39(14). México: Instituto Nacional de Antropología e Historia.

. (2006). Etnología de la danza rarámuri en la Sierra Tarahumara. España: Editorial Universidad de Granada.

Bennett, C., y Robert M. (1978). Los tarahumara, una tribu del norte de México. México: Instituto Nacional Indigenista.

Bonfiglioli, C. (1995). Fariseos y matachines en la Sierra Tarahumara. Entre la pasión de Cristo, la transgresión cómico sexual y las danzas de Conquista. México: Instituto Nacional Indigenista.

Burgess, D. (1999). Hit and run. Natural History, 108(7). EE.UU: The Magazine of the American Museum of Natural History.

Burgess, D., y Merino, R. (2002). Cómo aprender rarámuri de la Tarahumara Baja. Chihuahua: Consejo Nacional para la Cultura y las Artes, Instituto Chihuahuense de la Cultura. 
Cazeneuve, J. (1971). Sociología del rito. Buenos Aires: Amorrortu.

Deledalle, G. (1996). Leer a Peirce hoy. Gedisa, Barcelona.

Fujigaki, J. (2009). La muerte y sus metáforas. Ensayo sobre la ritualidad mortuoria y sacrificial rarámuri en el noroeste de México. México: Tesis de Maestría en Antropología, Instituto de Investigaciones Antropológicas-Facultad de Filosofía y Letras, Universidad Nacional Autónoma de México.

Garrido, J. P. (2006). Sistema ritual-festivo en la barranca tarahumara: el caso de la comunidad rarámuri Guadalupe Coronado, Tesis de Licenciatura, Escuela Nacional de Antropología e Historia, México.

. (2011). Danza y contexto: el pascol rarámuri en la Baja Tarahumara, Universidad Nacional Autónoma de México/FFyL-IIA, México.

Garrido, J. P y Nicolás O. (2012). Rarámuri Stories from Before: Rarámuri Historias de antes, en: David L. Kozak (eds.), "Inside Dazzling Mountains of Southwest Native Verbal Arts", The University of Nebraska Press, EUA, pp. 317-336.

Garrido, J. P. (2012). Ritos preventivos y metáforas en la baja tarahumara, en: Arturo Gutiérrez del Ángel (eds.), "Hilando el Noroeste", El Colegio de San Luis A.C., México, pp. 281-301.

González, L. (1993). El noroeste novohispano en la época colonial. México: Instituto de Investigaciones Antropológicas/Miguel Ángel Porrúa.

. (1984). Crónicas de la Sierra Tarahumara. México: Secretaria de Educación Pública, $1^{\text {a }}$. edición.

(1982). Tarahumara la Sierra y el hombre. México: Secretaria de Educación Pública y Fondo de Cultura Económica.

Lehn, E., y Olivos, N. (2005). Rarámuri. Vivir en la tarahumara. México: Secretaria de Educación Pública y Nostra Ediciones.

Lenh, E. (2008). Archivo Visual, música tarahumara: el Pascol rarámuri de la Baja Tarahumara. México.

Lumholtz, C. (1986). El México desconocido. Instituto Nacional Indigenista, tomo I, (ed.), Facsimilar. México. 
Luna, R. (2006). Estructura y organización social en la tarahumara: los impactos de la migración y el narcocultivo en una comunidad rarámuri, México: Tesis de licenciatura. Escuela Nacional de Antropología e Historia.

Martínez, M. (2008). Los caminos rarámuri. Persona y cosmos en el noroeste de México. México: Tesis de Maestría en Antropología, Instituto de Investigaciones Antropológicas-Facultad de Filosofía y Letras, Universidad Nacional Autónoma de México.

Merrill, W. (1992). El catolicismo y la creación de la religión moderna de los rarámuris. Ysla Campbell (ed.). El Contacto entre los Españoles e Indígenas en el Norte de la Nueva España, (en Colección conmemorativa quinto centenario del encuentro de dos mundos), Universidad Autónoma de Ciudad Juárez.

. (1992). Almas rarámuri. México: Instituto Nacional Indigenista y Consejo Nacional para la Cultura y las Artes.

Molina, M. (2003). Pascolas y chapayecas: problematización de la figura del bufón ritual (ritual clown) en los dos personajes enmascarados del ceremonial yaqui. México: Tesis de licenciatura, Universidad Autónoma de México-Iztapalapa.

Peirce, Ch. (1987). Obra lógico-semiótica. España: Taurus. . (1997). Escritos filosóficos. México: El Colegio de Michoacán, Volumen I. . (1986). La ciencia de la semiótica. Buenos Aires: Nueva Visión.

Pike, K. (1967). Language, in Relation to a Unified Theory of Structure of Human Behavior, $2^{\text {nd }}$. edición. Paris: The Hague, Mouton.

Pintado, A. (2007). Los hijos de rioso y riablo: fiestas grandes y resistencia cultural en una comunidad tarahumara de la barranca. México: Tesis de Doctorado. Instituto de Investigaciones Antropológicas, Universidad Nacional Autónoma de México, México.

Sánchez, P. (2008). La inversión del cosmos. Danzas, rituales y mitos en la región yoreme. México: Tesis de Licenciatura. Escuela Nacional de Antropología e Historia.

Sandoval, E. (2006). Homenaje a Charles Sanders Peirce. México: Universidad Autónoma de la Ciudad de México. 
Saussure, F. (1985). Curso de lingüística general. México: Editorial Planeta.

Scheffler, I. (1997). Symbolic Worlds. Art, Science, Language, Ritual. Cambridge University Press.

Velasco, P. (1987). Danzar o morir. Religión y resistencia a la dominación en la cultura tarahumar. México: Centro de Reflexión Teológica. 